\title{
Report on Broadband Solar Radiometer Inconsistencies at the Atmospheric Radiation Measurement (ARM) Southern Great Plains (SGP) Central Facility During the ARM Enhanced Shortwave Experiment (ARESE)
}

1996

C. N. Long

Work supported by the U.S. Department of Energy,

Office of Energy Research, Office of Health and Environmental Research 


\section{Contents}

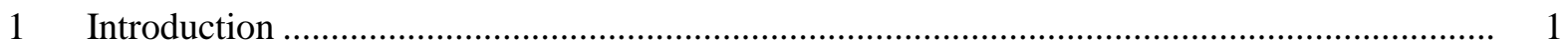

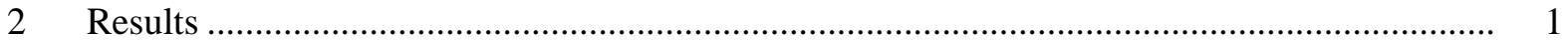

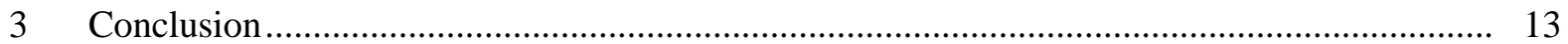




\section{Figures}

1 Comparison of SGP CF SIROS and BSRN Total SW for mostly clear days.......................... 2

2 Comparison of SGP CF SIROS and BSRN Diffuse SW for mostly clear days. ...................... 2

3 Comparison of SGP CF SIROS and BSRN Direct Normal SW for mostly clear days............. 3

4 SW total, direct and diffuse from the SGP BSRN and SIROS radiometers for

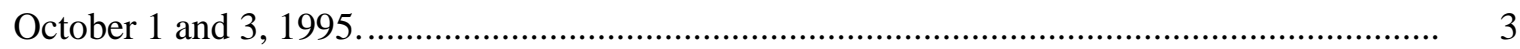

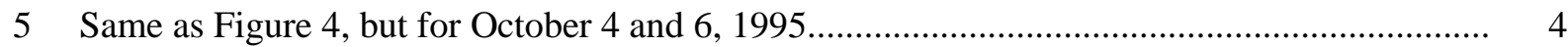

6 Same as Figure 4, but for October 14 and 20, 1995 ......................................................... 4

7 Diffuse disagreement as a percentage of the SIROS diffuse for October 14, 1995_................ 5

8 Total SW disagreement as a percentage of the SIROS value for mostly clear days................... 6

9 Diffuse SW disagreement as a parentage of the SIROS value for mostly clear days................ 6

10 Direct Normal SW disagreement as a percentage of the SIROS value for mostly clear days... 7

11 Total SW disagreement as a percentage of the SIROS value by cosine of the solar zenith angle for data after October 14, 1995.

12 Total SW irradiance disagreement by cosine of the solar zenith angle for clear-skies,

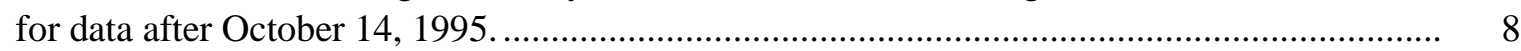

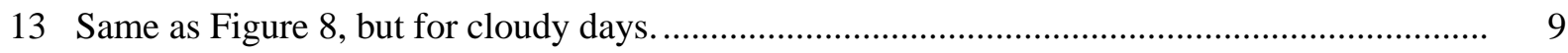

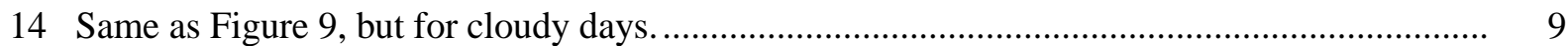

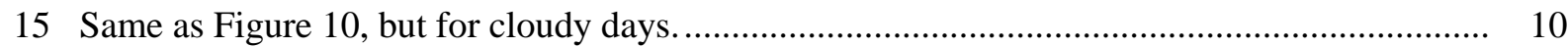

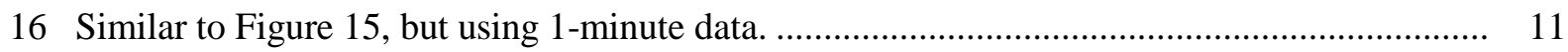

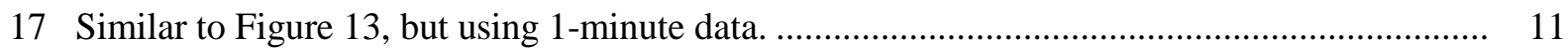

18 Similar to Figure 14, but using 1-minute data. ................................................................. 12

19 Standard Deviation from perfect agreement $(\mathrm{X}=\mathrm{Y})$ for increasing averaging times for mostly clear and cloudy days for Total SW, Diffuse SW, and Direct Normal SW.................. 13 


\section{Introduction}

Broadband solar radiometer data collected at the U.S. Department of Energy's Atmospheric Radiation Measurement (ARM) Southern Great Plains (SGP) Central Facility during the ARM Enhanced Shortwave Experiment (ARESE) exhibits inconsistencies and inter-calibration offsets. This report examines these problems, and in some cases, suggests error sources and possible solutions. The data discussed here covers the period from September 28, 1995, through October 30, 1995. Prior to that, the Baseline Surface Radiation Network (BSRN) radiometer data were not being logged for about $2 \frac{1}{2}$ weeks. This problem was not rectified until we inquired about the data for September 27, 1995, in support of an ARESE analysis. Most of the following discussion is based on 5-minute averages of the data. Site reports state that on October 13,1995, the BSRN total shortwave (SW) pyranometer was changed to a newly calibrated one; therefore, much of the analysis has been split into the period before the $14^{\text {th }}$ and after the $14^{\text {th }}$. The latter is noted on the graphs as after the $14^{\text {th }}$, but does include the $14^{\text {th }}$ data. Concern was initially raised by an attempt to use BSRN and Solar and Infrared Observing System (SIROS) data to calibrate total and diffuse measurements from a rotating-arm instrument system currently under development at the Pennsylvania State University. In addition, we wanted the most accurate measurements for verification of clear-sky SW irradiance calculations by a model currently undergoing development.

\section{Results}

Figures 1, 2, and 3 show a comparison of the direct normal, diffuse, and total SW measurements, respectively, for the mostly clear days in the time period. The standard deviation (StDev) from perfect agreement ( $\mathrm{X}=\mathrm{Y}$ on the graphs) is calculated for each plot to illustrate how much one set of measurements agrees with the other. The standard deviation is about $24 \mathrm{Wm}-2$ for the direct normal (Figure 3), excluding the period when the BSRN instrument had a problem and read only a few Wm-2 continuously for a few days. For the diffuse measurements, separating out times when the wind blew the BSRN shading disc arm out of alignment is difficult, and no attempt has been made to delete these data from the analysis. Thus, the diffuse standard deviations $(59.3 \mathrm{Wm}-2)$ after the $14^{\text {th }}$ are greater than they would be if quality control of the data were applied. For the mostly clear days prior to the $14^{\text {th }}$, this problem doesn't seem to have occurred, giving a standard deviation of about $10 \mathrm{Wm}-2$ (Figure 2). The total SW BSRN calibration seems to have drifted during the period before the $14^{\text {th }}$ (Figure 1). This results in a "better" standard deviation of $15 \mathrm{Wm}-2$ before the $14^{\text {th }}$ than the $21 \mathrm{Wm}-2$ apparent offset from the $14^{\text {th }}$ on. This drifting about can be seen in Figures 4, 5, and 6, which show sample time series of the data. In these graphs, the dashed lines represent the SIROS data and the solid lines represent BSRN. For October $1^{\text {st }}$ and $3^{\text {rd }}$ (Figure 4), the BSRN direct normal was inoperative, and the SIROS total SW was greater than the BSRN by about $40 \mathrm{Wm}-2$ to $50 \mathrm{Wm}-2$ near local solar noon. By October $4^{\text {th }}$ and $6^{\text {th }}$ (Figure 5 ), the BSRN direct normal was back on line and different from the SIROS instrument by about $20 \mathrm{Wm}-2$ to $25 \mathrm{Wm}-2$ at local noon. The two total SW instruments are almost in agreement. October $14^{\text {th }}$ and $20^{\text {th }}$ (Figure 6) show the same offset for the direct normals, but now the SIROS total SW is less than the BSRN by about $20 \mathrm{Wm}-2$ to $25 \mathrm{Wm}-2$ near local solar noon. In all three figures, the SIROS diffuse is less than the BSRN by varying amounts. 


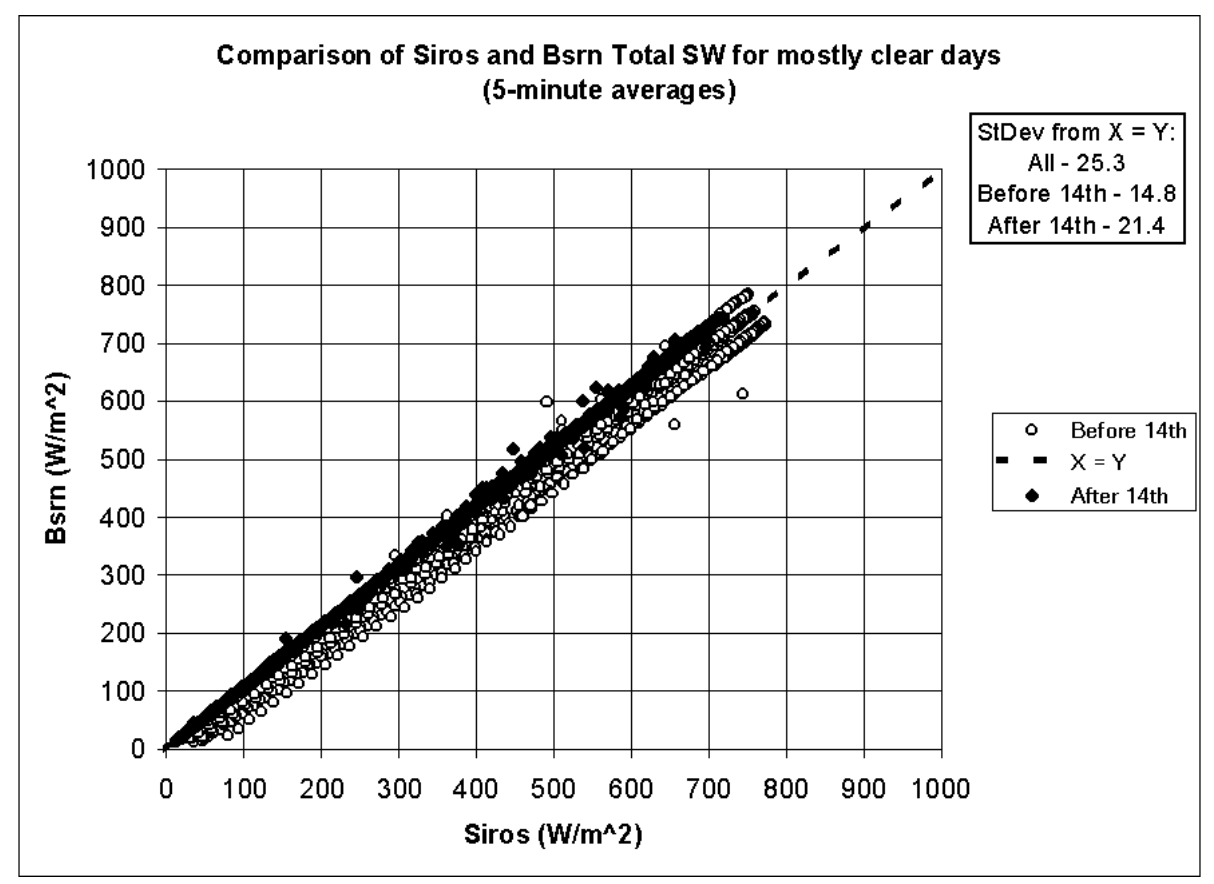

Figure 1. Comparison of SGP CF SIROS and BSRN Total SW for mostly clear days.

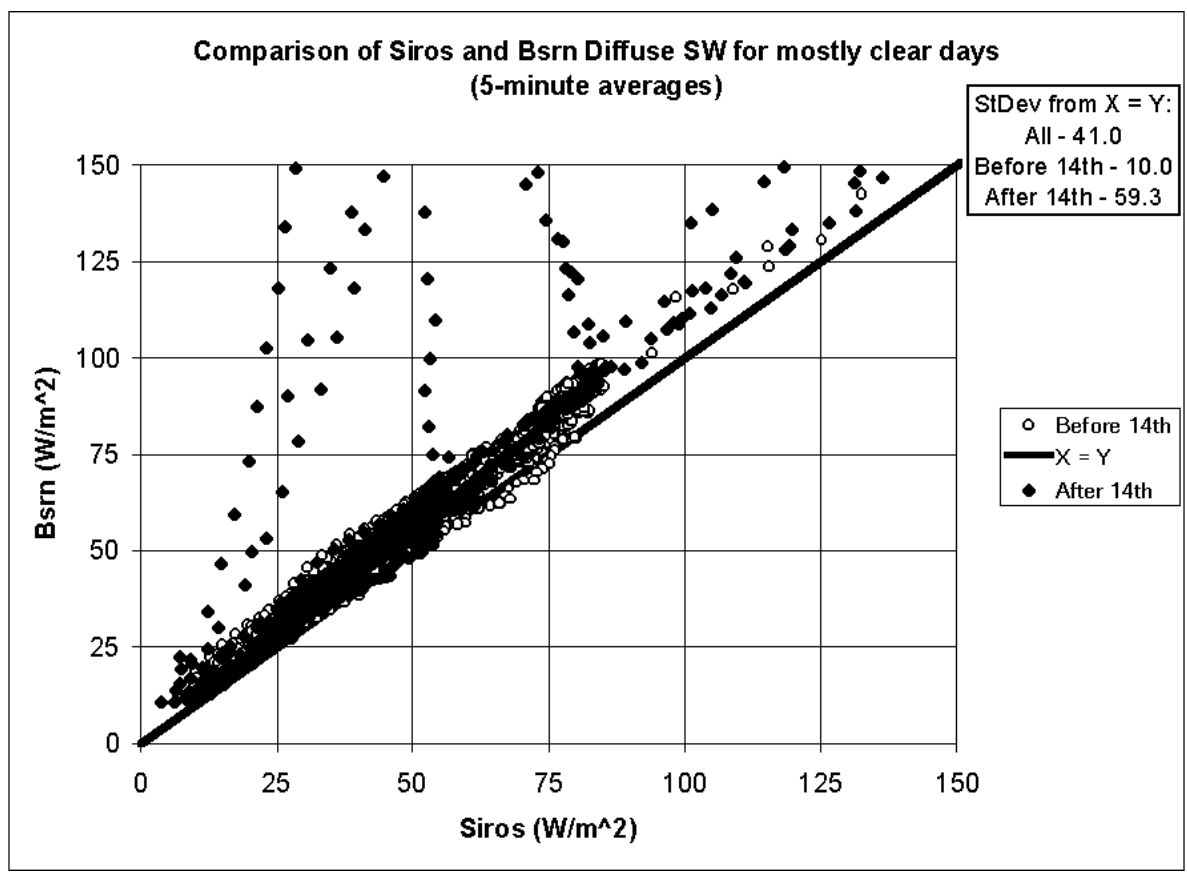

Figure 2. Comparison of SGP CF SIROS and BSRN Diffuse SW for mostly clear days. 


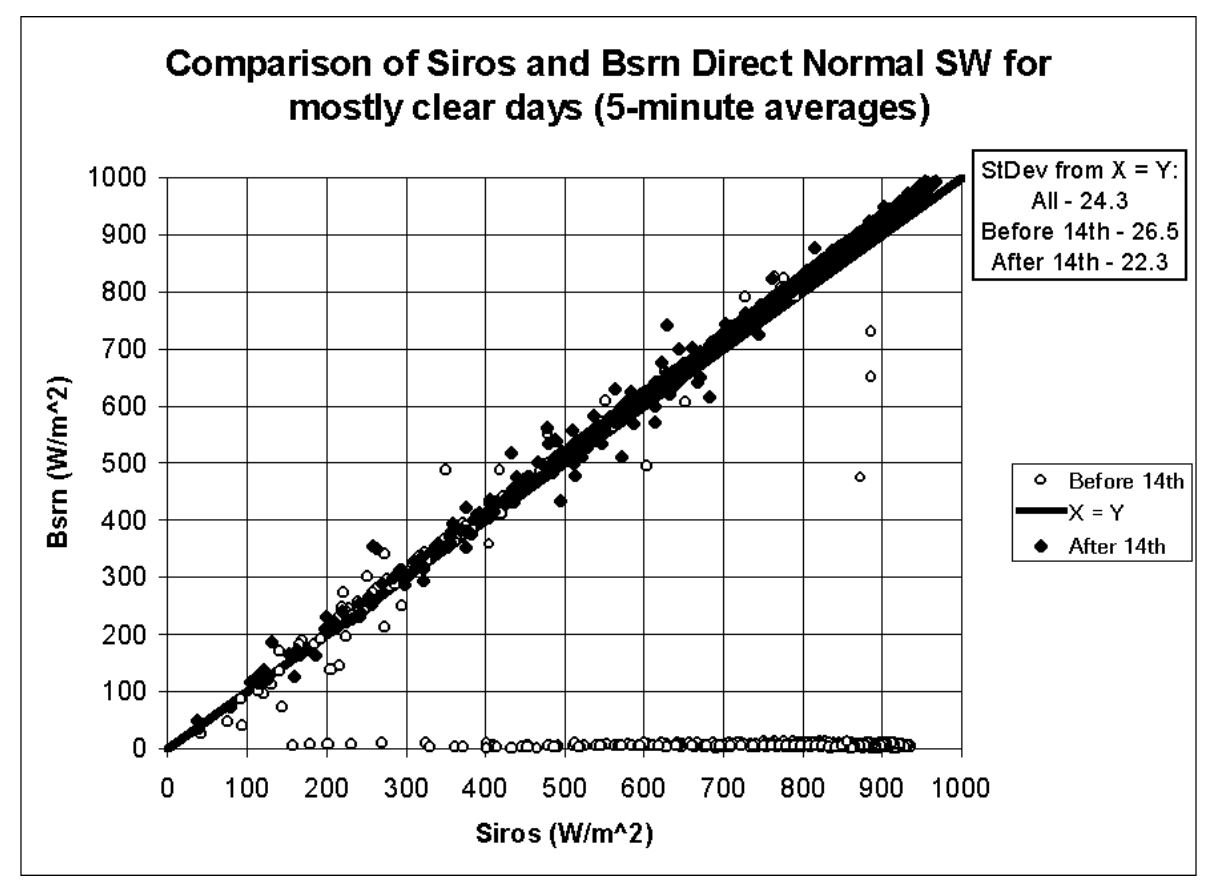

Figure 3. Comparison of SGP CF SIROS and BSRN Direct Normal SW for mostly clear days.

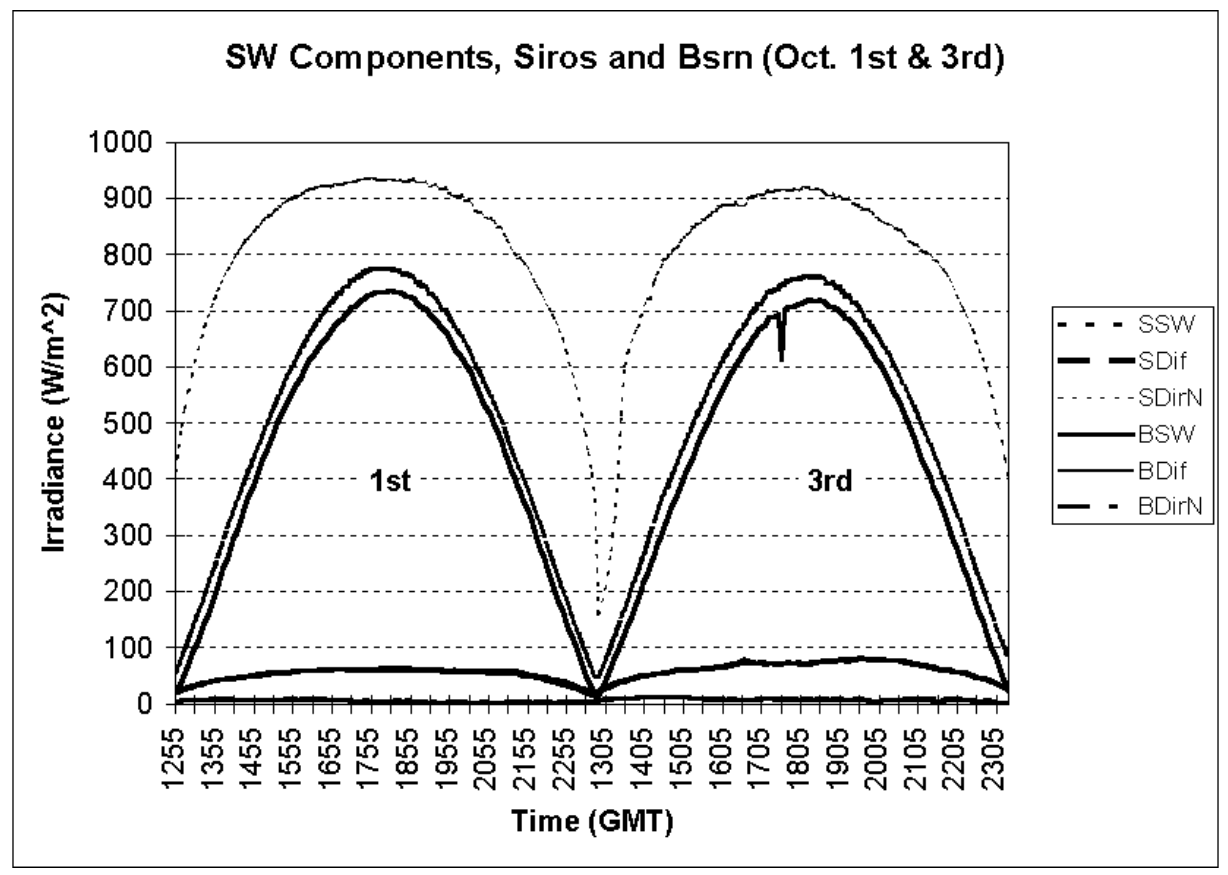

Figure 4. SW total, direct and diffuse from the SGP BSRN and SIROS radiometers for October 1 and 3, 1995. 


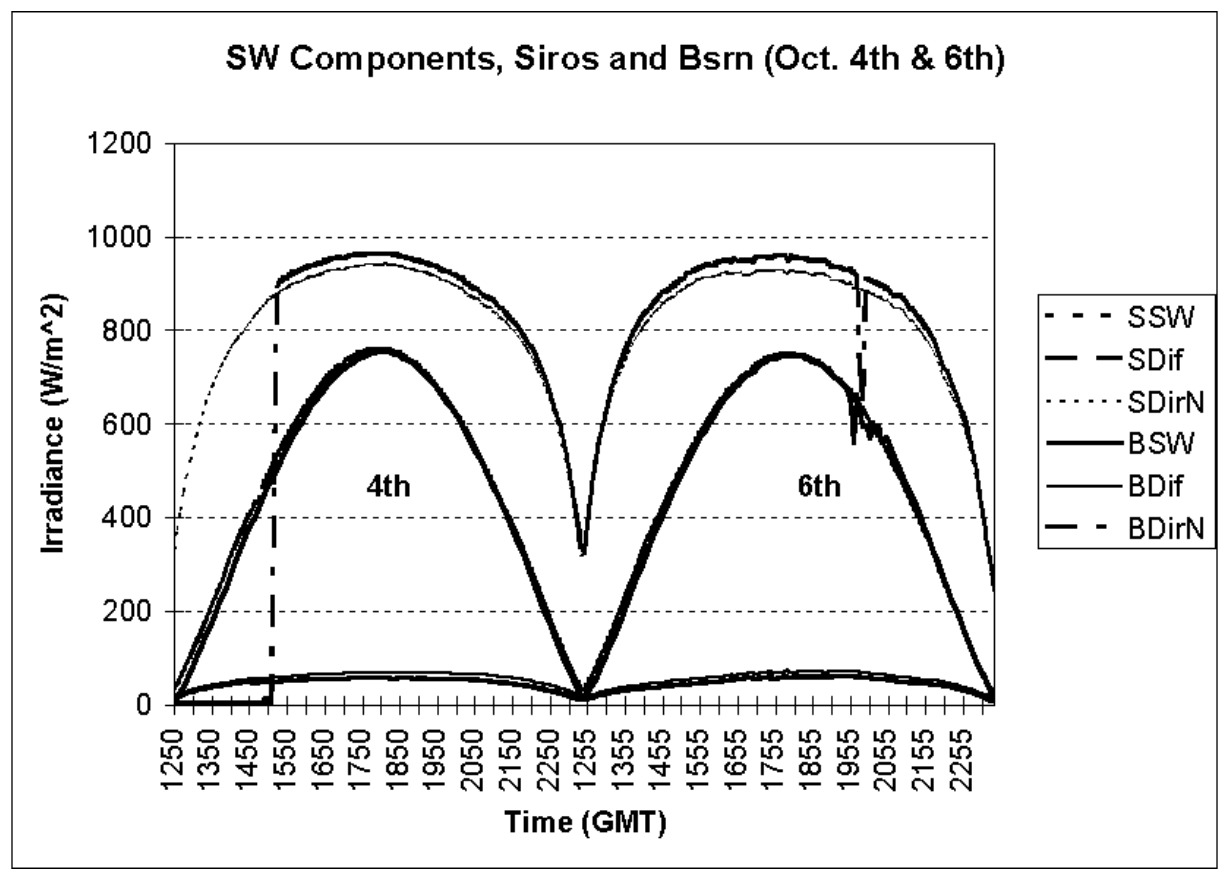

Figure 5. Same as Figure 4, but for October 4 and 6, 1995.

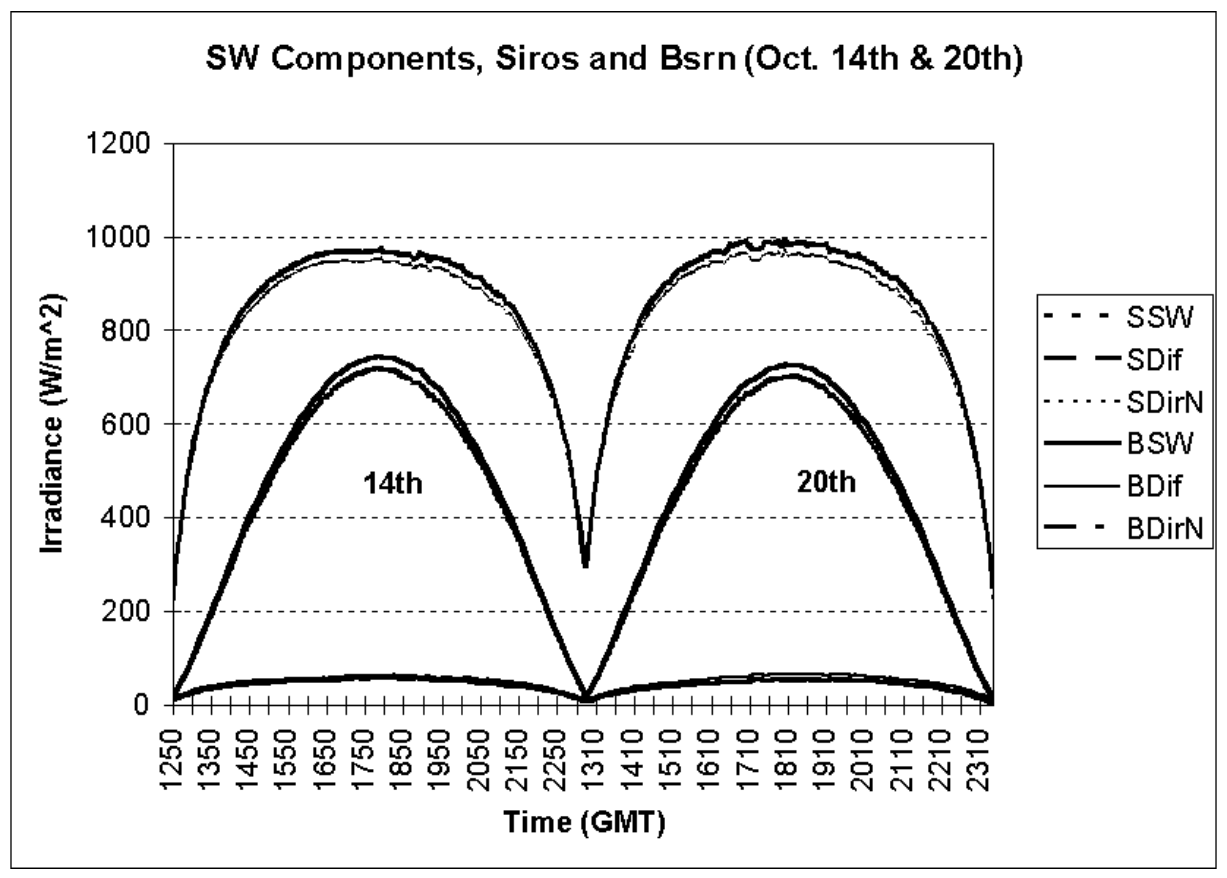

Figure 6. Same as Figure 4, but for October 14 and 20, 1995. 
Figure 7 shows a percent error time series for the diffuse instruments for October $14^{\text {th }}$, which we have determined was one of the clearest days during ARESE in terms of aerosol loading. The error is calculated by differencing the SIROS and BSRN measurements and then dividing by the SIROS measurement. The smooth curve represents a running mean through the data. This plot shows two features of the diffuse measurements. First, while the error is greater at larger solar zenith angles, the average for the day is about $13 \%$. Second, even for a very clear day and using 5-minute averages of the data, this error varies considerably for consecutive measurements. The differences in these measurements are addressed later in the discussion of the signal-to-noise problem.

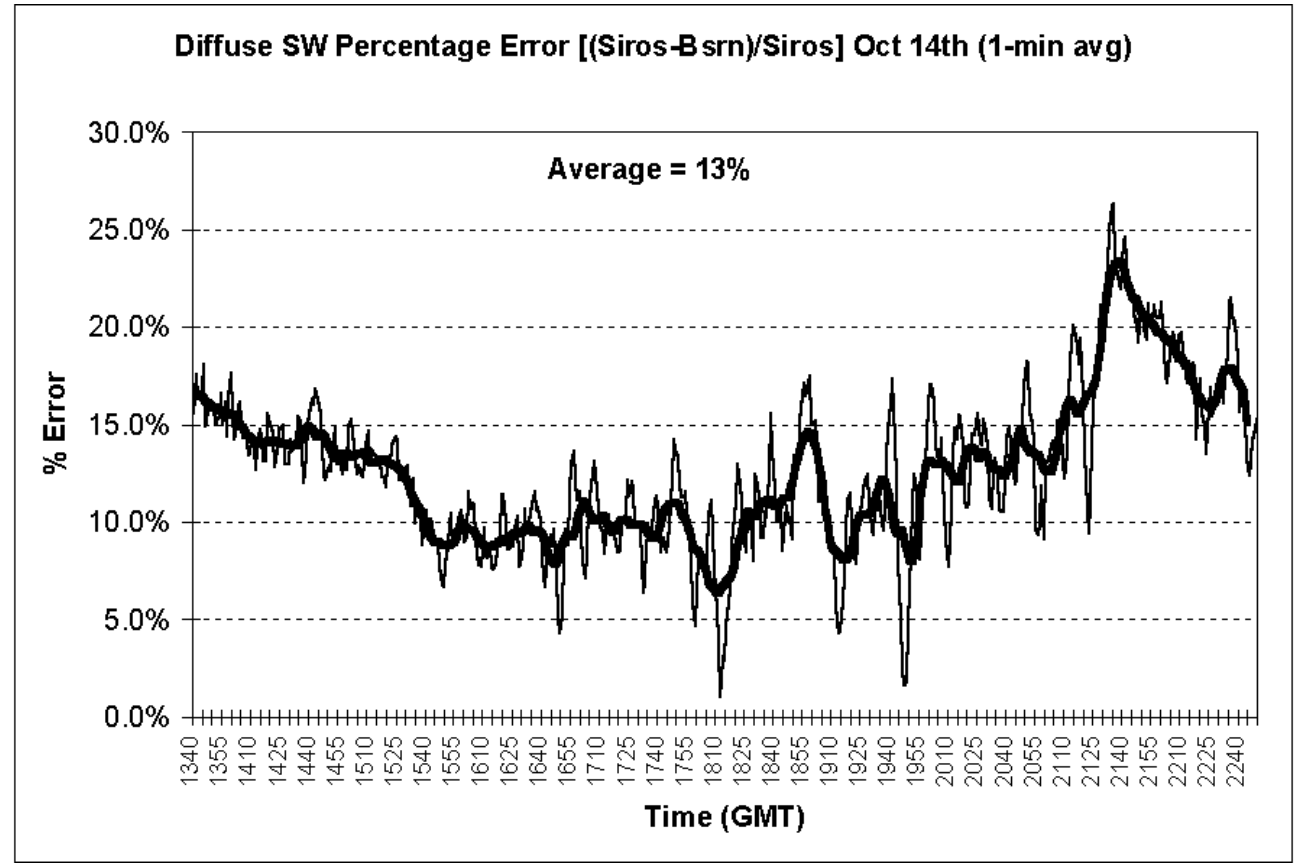

Figure 7. Diffuse disagreement as a percentage of the SIROS diffuse for October 14, 1995.

This same type of error analysis for the entire ARESE period is given in Figures 8, 9, and 10 for the total, diffuse, and direct normal respectively. Note that these figures contain data only from the mostly clear days during ARESE. The error improves for the total SW (Figure 8) from the $14^{\text {th }}$ on, exhibiting values from $20 \%$ (early morning and late evening) to about $5 \%$ near local solar noon. The diffuse measurements (Figure 9), however, show a wide scatter in error, with values around local noon ranging from near zero in a few instances to $25 \%$. Again the mean error of these series is around $13 \%$ to $15 \%$. The direct normal measurements (Figure 10) show the least error (5\% or less). However, this is due to the typically large magnitude of the measurements under clear conditions (about $800 \mathrm{Wm}-2$ to $1000 \mathrm{Wm}-2)$.

To further portray the offset between the SIROS and BSRN total solar radiometers, Figure 11 shows the $\%$ error after the $14^{\text {th }}$ for the mostly clear days by the cosine of the solar zenith angle. A function has been fit through the data points to give an idea of the average error. Given the nominal $10 \mathrm{Wm}-2$ to $15 \mathrm{Wm}-2$ accuracy of the Epply pyranometers and the cosine response characteristics, the percent error 


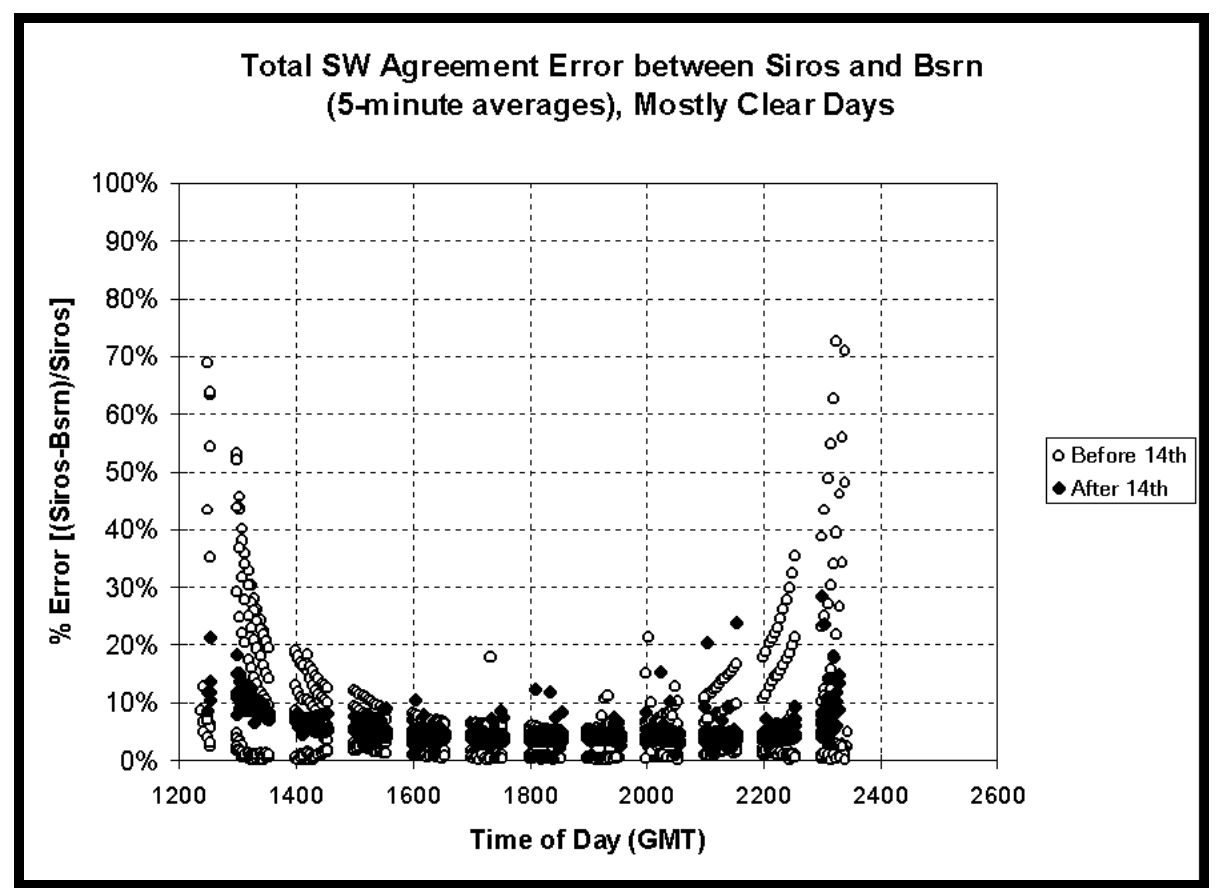

Figure 8. Total SW disagreement as a percentage of the SIROS value for mostly clear days.

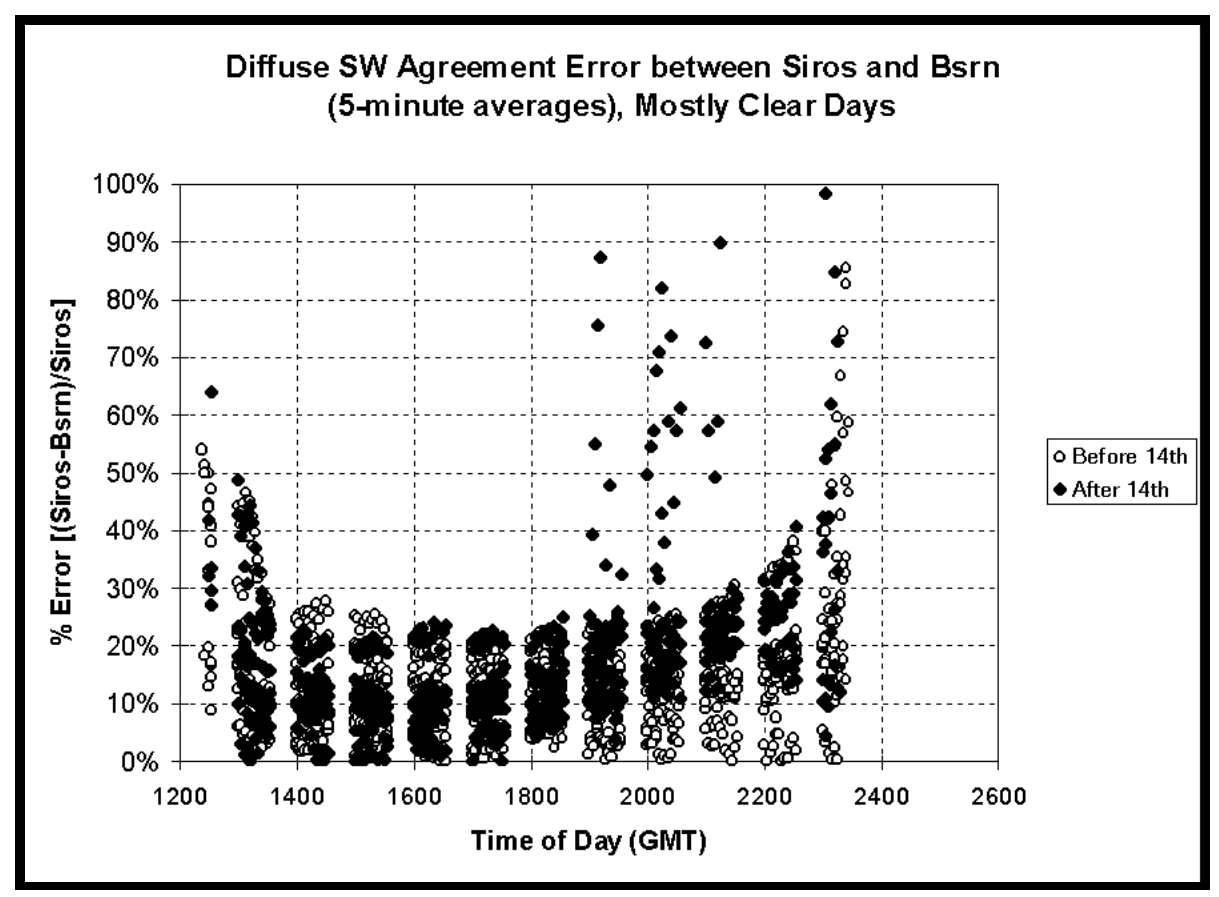

Figure 9. Diffuse SW disagreement as a parentage of the SIROS value for mostly clear days. 


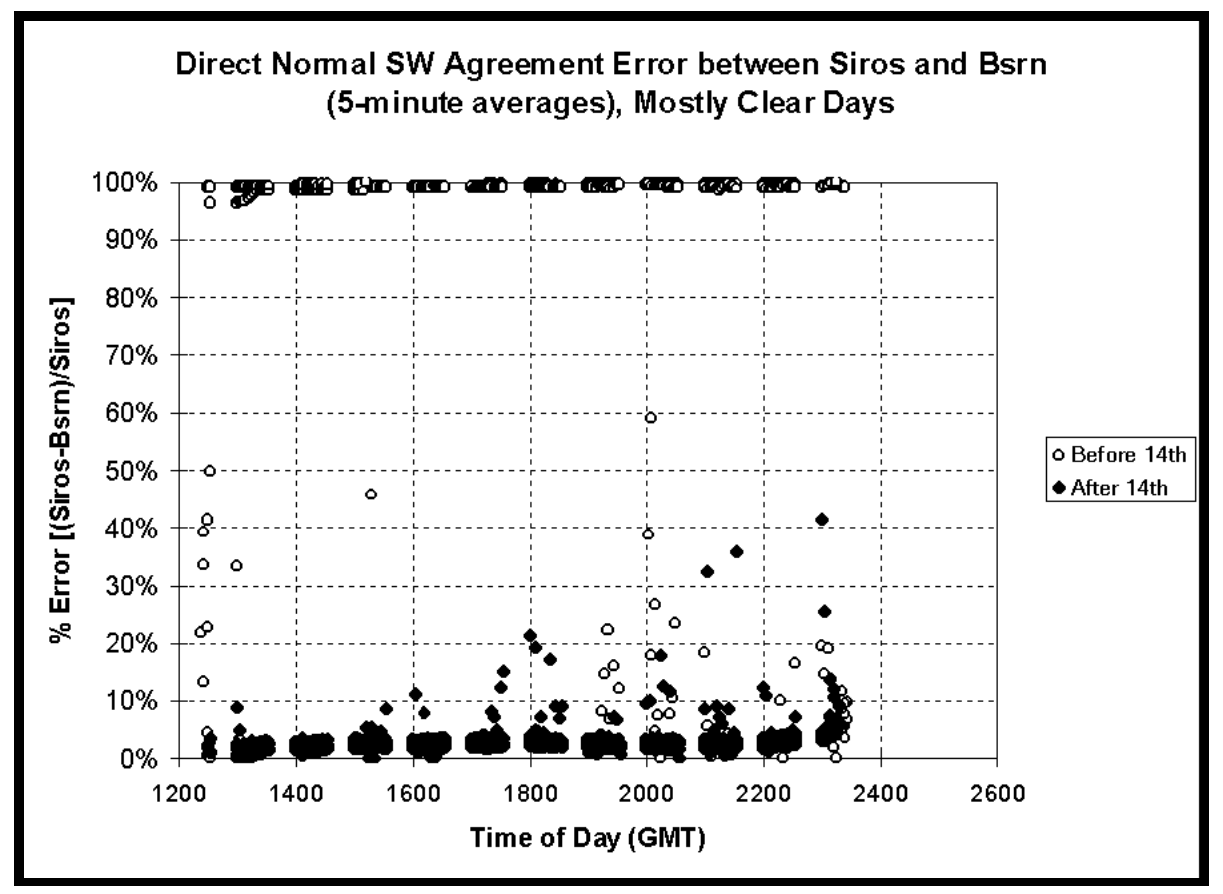

Figure 10. Direct Normal SW disagreement as a percentage of the SIROS value for mostly clear days.

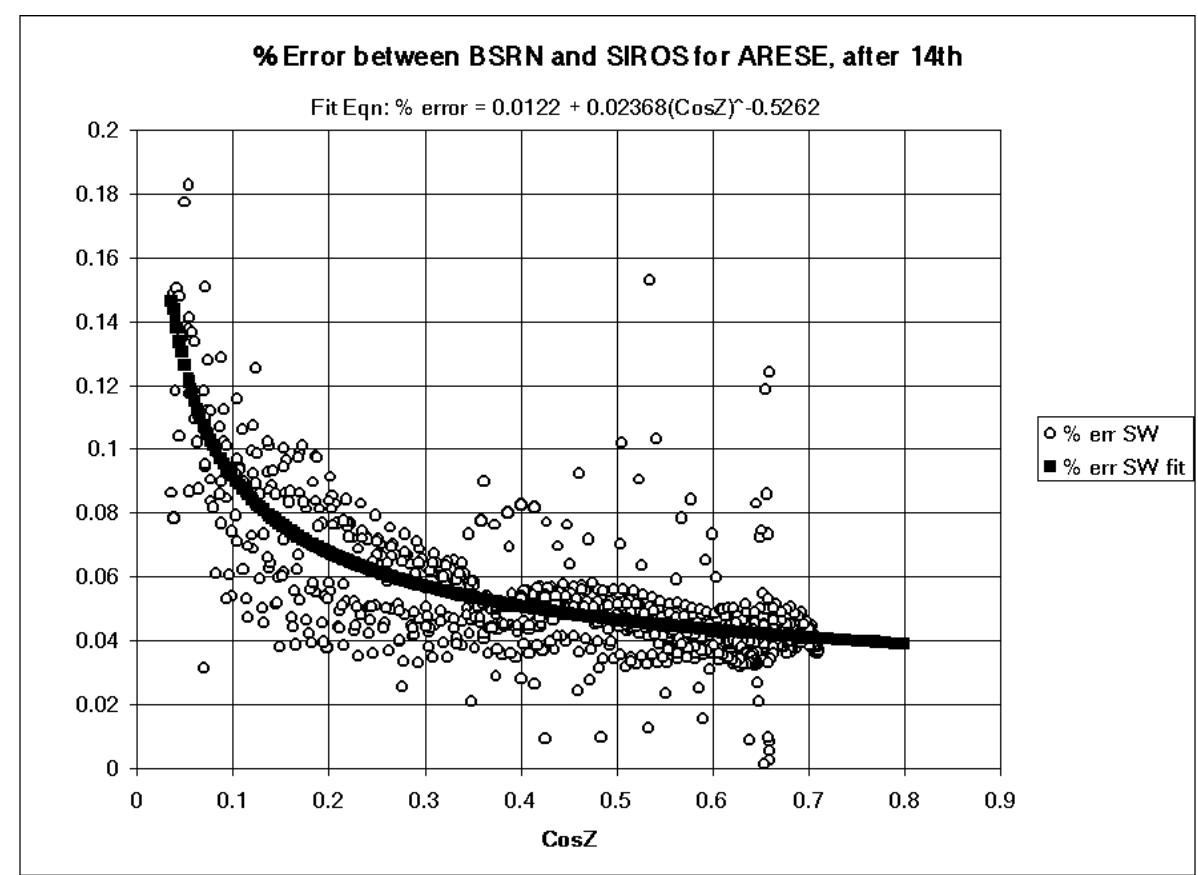

Figure 11. Total SW disagreement as a percentage of the SIROS value by cosine of the solar zenith angle for data after October 14, 1995. 
increases at greater zenith angles. This is not surprising since at greater zenith errors the magnitude of the irradiance is decreasing. Perhaps a more useful view is given in Figure 12, which shows the irradiance difference between the two radiometers after the $14^{\text {th }}$ as a function of CosZ. A linear fit through the data suggests that at local solar noon the average difference between the two radiometers is about $30 \mathrm{Wm}-2$, the BSRN system being the greater. Naturally, this difference decreases to a few Wm-2 at sunrise and sunset. The instrument output voltage is multiplied by a constant calibration factor, yet the total solar irradiance is not strictly a linear function of the cosine of the zenith angle. Thus, it is not easy to determine whether this mostly linear offset is strictly a calibration-offset problem, or is influenced by factors due to the different logging systems.

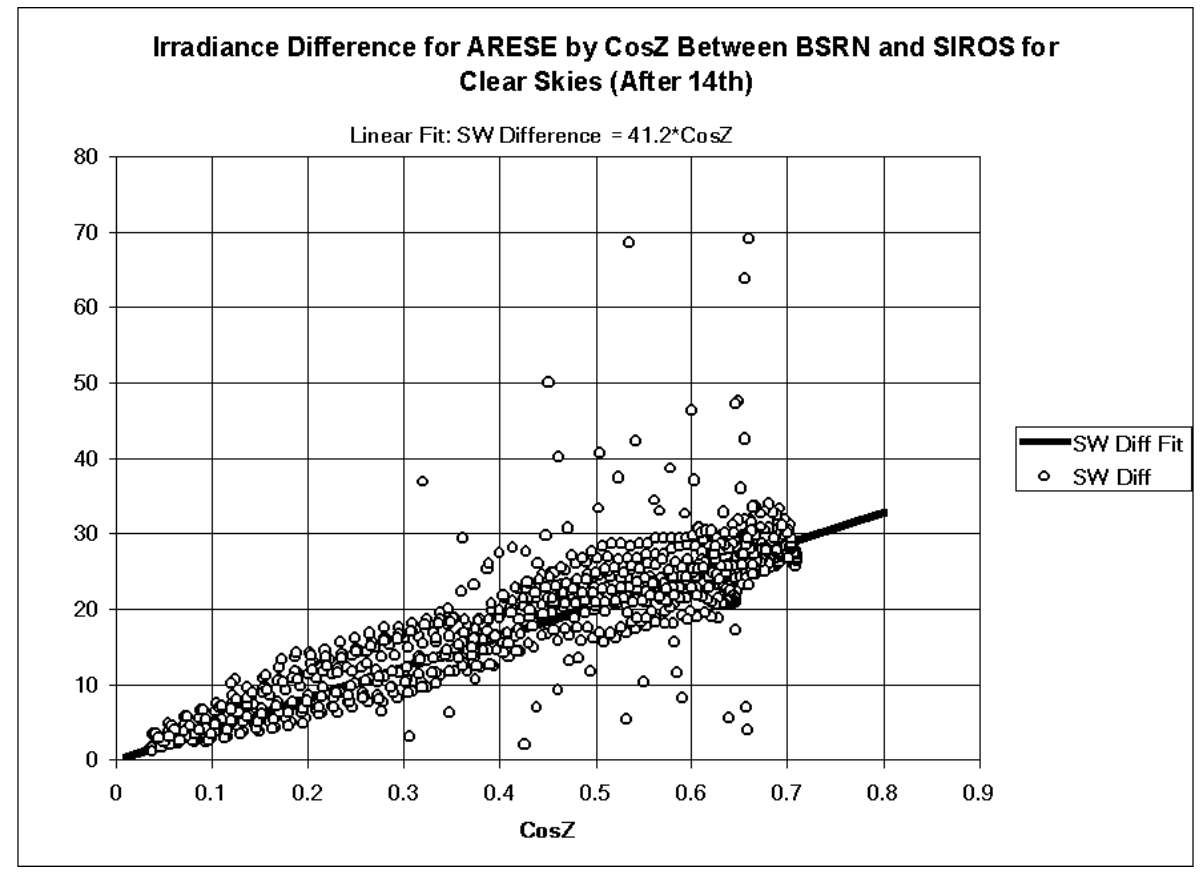

Figure 12. Total SW irradiance disagreement by cosine of the solar zenith angle for clearskies, for data after October 14, 1995.

The SW measurements show greater disagreement under cloudy conditions. Figures 13, 14, and 15 show the agreement error analysis for the remaining days of the time period. These days all exhibited clouds to some extent, ranging from slightly cloudy periods during the day to overcast periods. In many cases, the errors are similar to those on mostly clear days, because these measurements were taken during largely clear periods on days with broken clouds. But the increased disagreement exhibited by the remaining points is due to the presence of clouds. For the total SW (Figure 13), the error in the 5-minute averages increases to values of $50 \%$ in some cases at local solar noon, while the mean error increases over that for clear skies alone for all zenith angles. The diffuse error (Figure 14), on the other hand, is only marginally worse than that for clear days for the most part, although the extreme error values have increased. This is due to the slow-changing nature of the diffuse field for hemispheric measurements. The greatest change in error comes in the direct normal measurements (Figure 15). In this plot, most (but not all) of the values near $100 \%$ are due to the BSRN instrument malfunction. The clear error values 


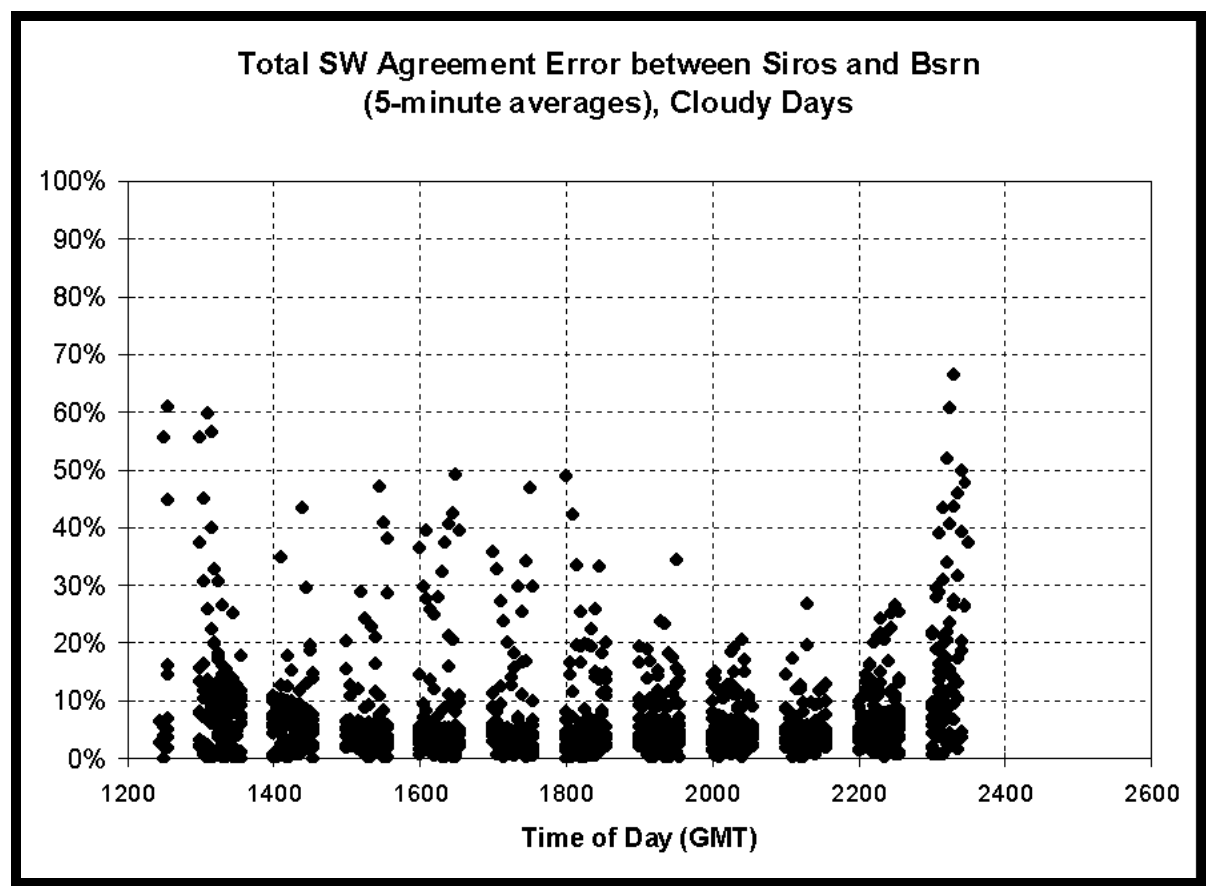

Figure 13. Same as Figure 8, but for cloudy days.

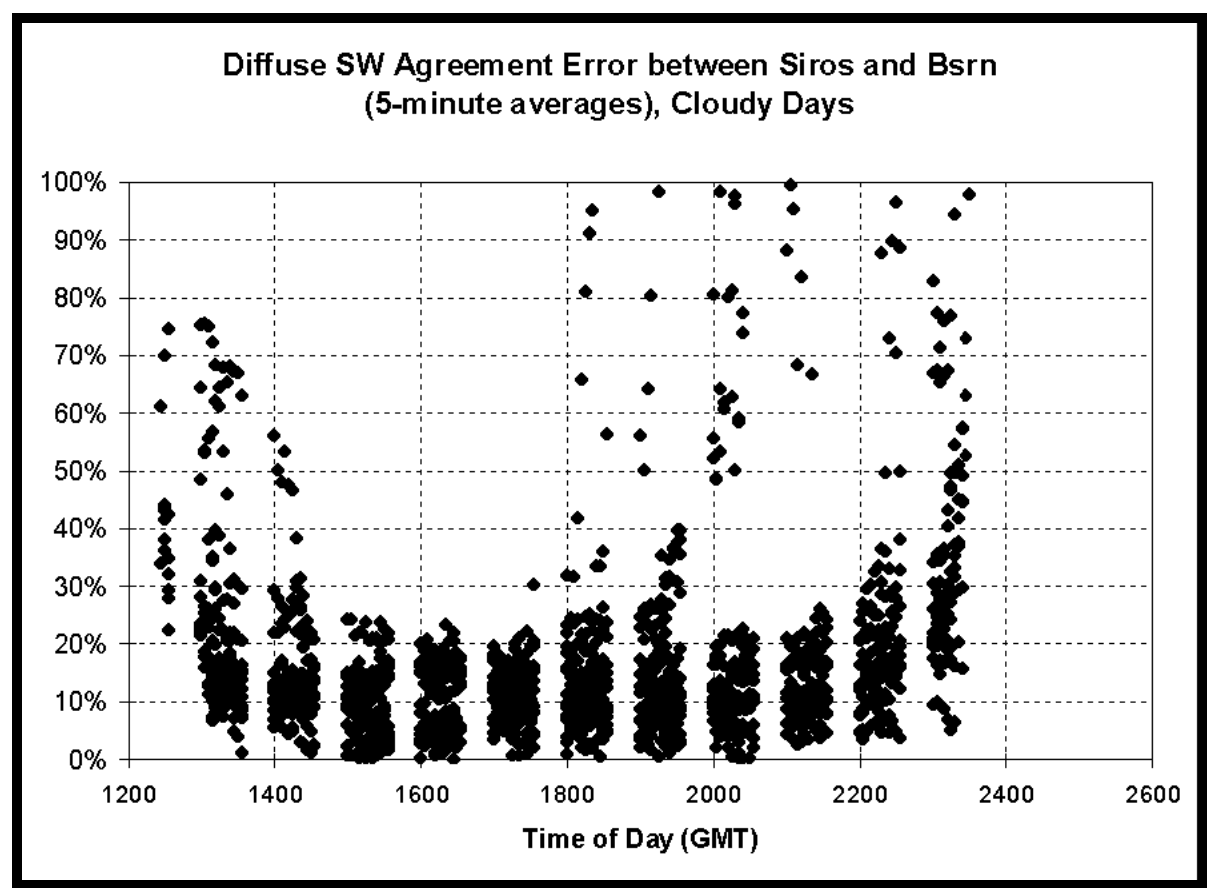

Figure 14. Same as Figure 9, but for cloudy days. 


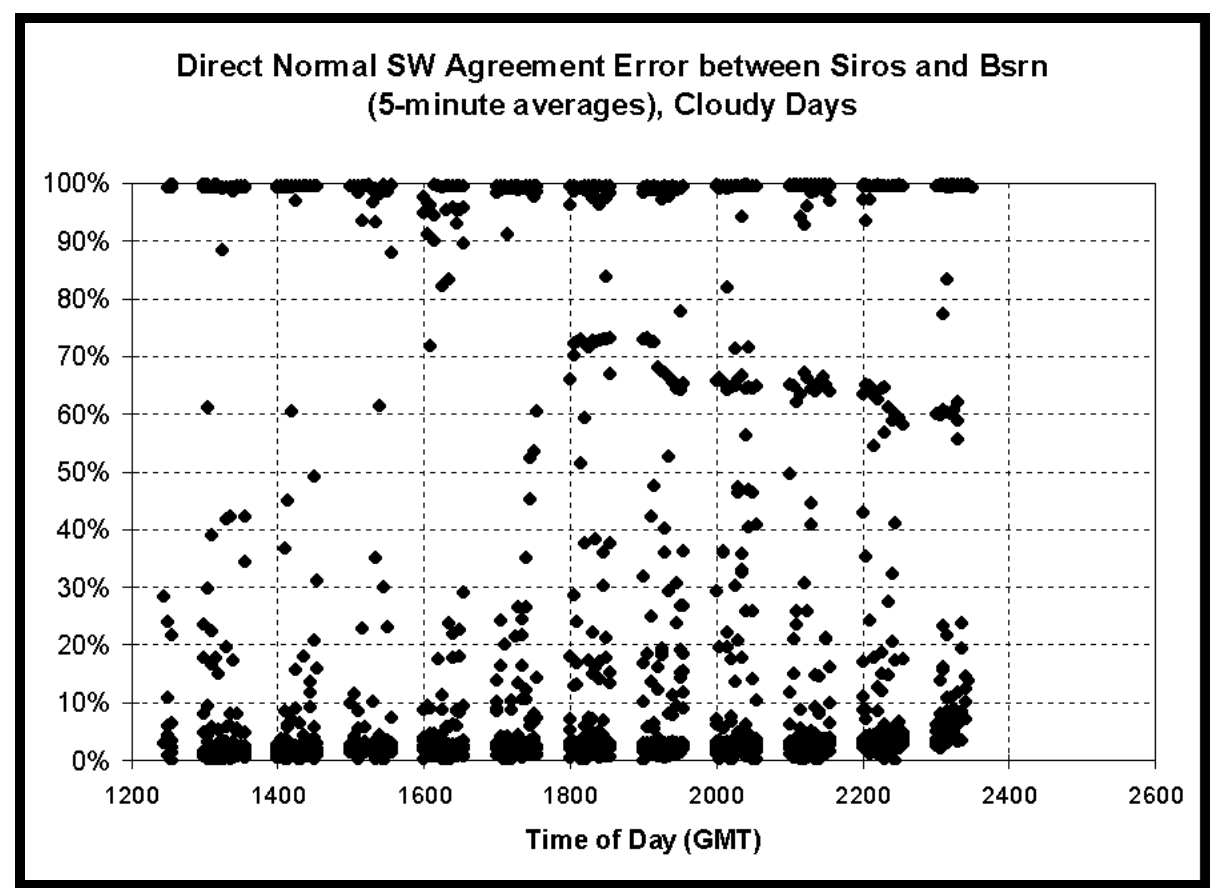

Figure 15. Same as Figure 10, but for cloudy days.

(Figure 10) suggest that the other large differences are not due to tracking problems by the instrument mounts. The spread of these error values is instead due to the differences in the way in which the data is being logged by the two platforms.

The SIROS measurements of total, diffuse, and direct normal SW consist of near instantaneous "snapshots" taken every 20 seconds. The BSRN platform, on the other hand, logs full 1-minute averages of the measurements. Under the highly varying radiation field that occurs during cloudy periods, this difference in logging methods makes comparisons between the instruments useless unless the data is averaged for long time periods. Figure 16 shows an error analysis of the direct normal measurements using BSRN 1-minute data and 1-minute averages of the SIROS data for the same days as Figure 15. The plot contains a total of 4000 points. Note the vertical scale of this plot, which must be expanded to show the wide range of error in the comparison. In this graph, all times when the BSRN direct normal system was inoperative have been removed. Not shown, in order to clearly view the majority of the scatter, are some of the values, which exceeded $300 \%$ error, including values as high as $800 \%$. These results are directly attributable to the difference in data logging between the two platforms. This suggests that the SIROS data is problematic for radiative studies at temporal resolutions of 1 to 15 minutes, such as comparisons with aircraft over-flight data for ARESE given the brief amount of time the aircraft are actually over the site on each pass.

The same problem is exhibited in Figure 17, which is a 1-minute comparison of 4000 samples of the total SW. The vertical scale for this plot covers 0 to $200 \%$ error, with the majority of the points in the range $0 \%$ to $50 \%$ error. Given a total $\mathrm{SW}$ of only $200 \mathrm{Wm}-2$, as is typical under overcast skies, this is 


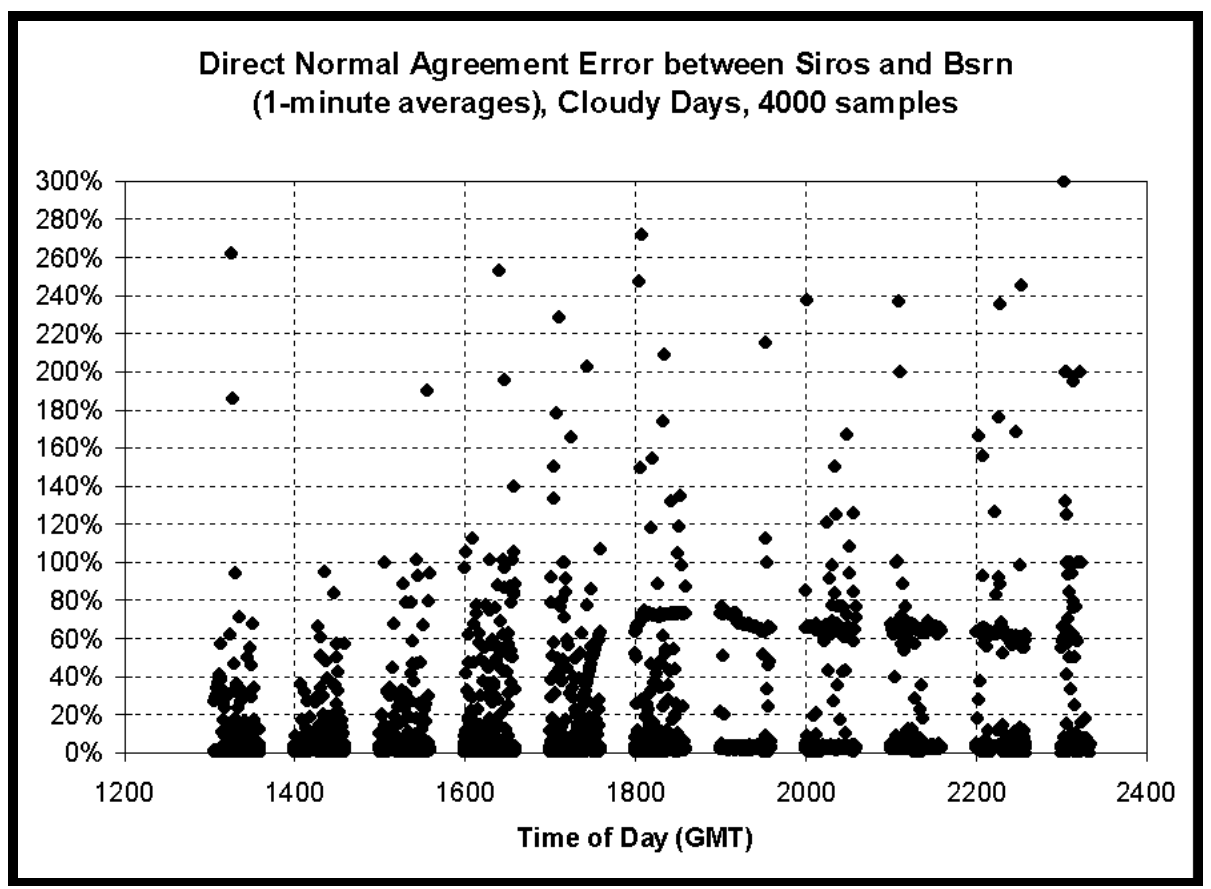

Figure 16. Similar to Figure 15, but using 1-minute data.

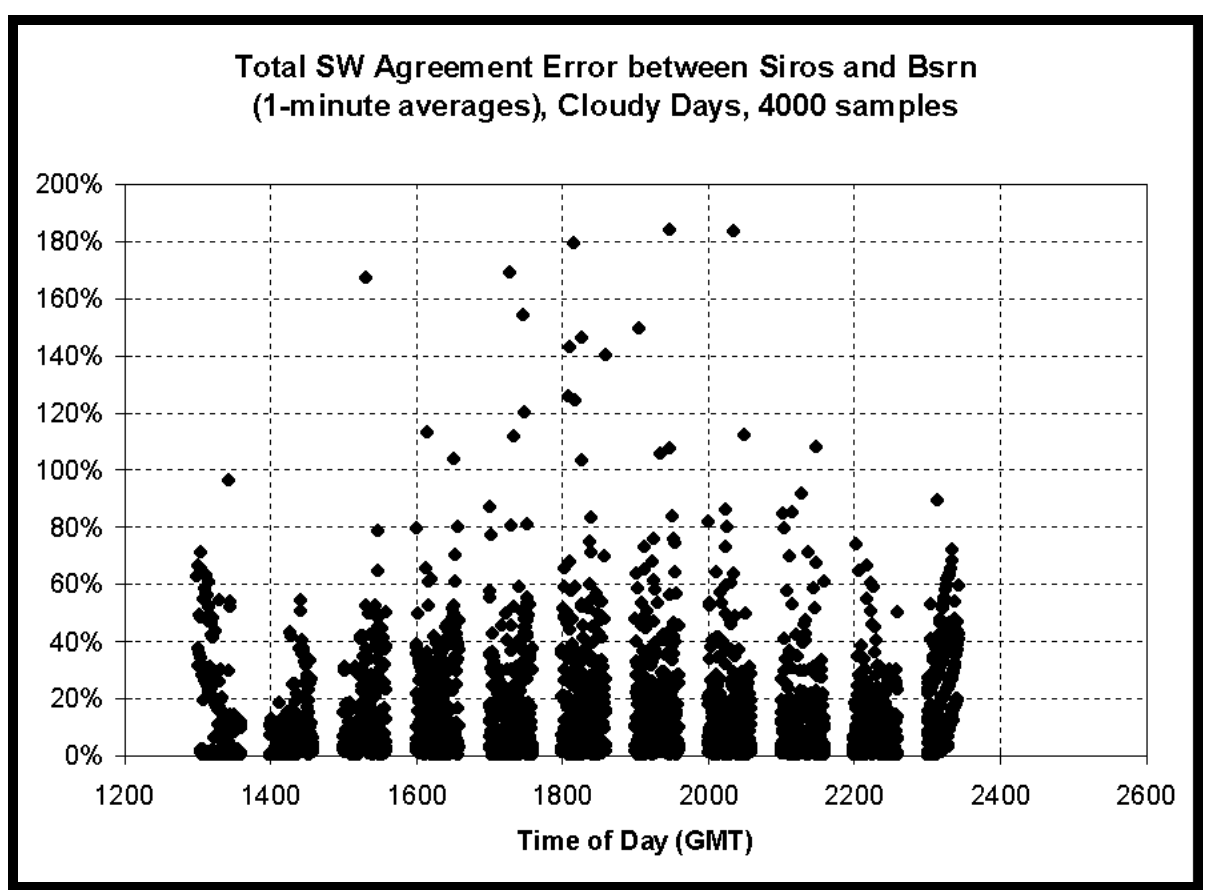

Figure 17. Similar to Figure 13, but using 1-minute data. 
still a difference of up to $100 \mathrm{Wm}-2$. Again, due to the nature of the field, this particular problem is not as evident in the diffuse SW measurements shown in Figure 18, with errors typically still in the range of $0 \%$ to $20 \%$ for smaller solar zenith angles.

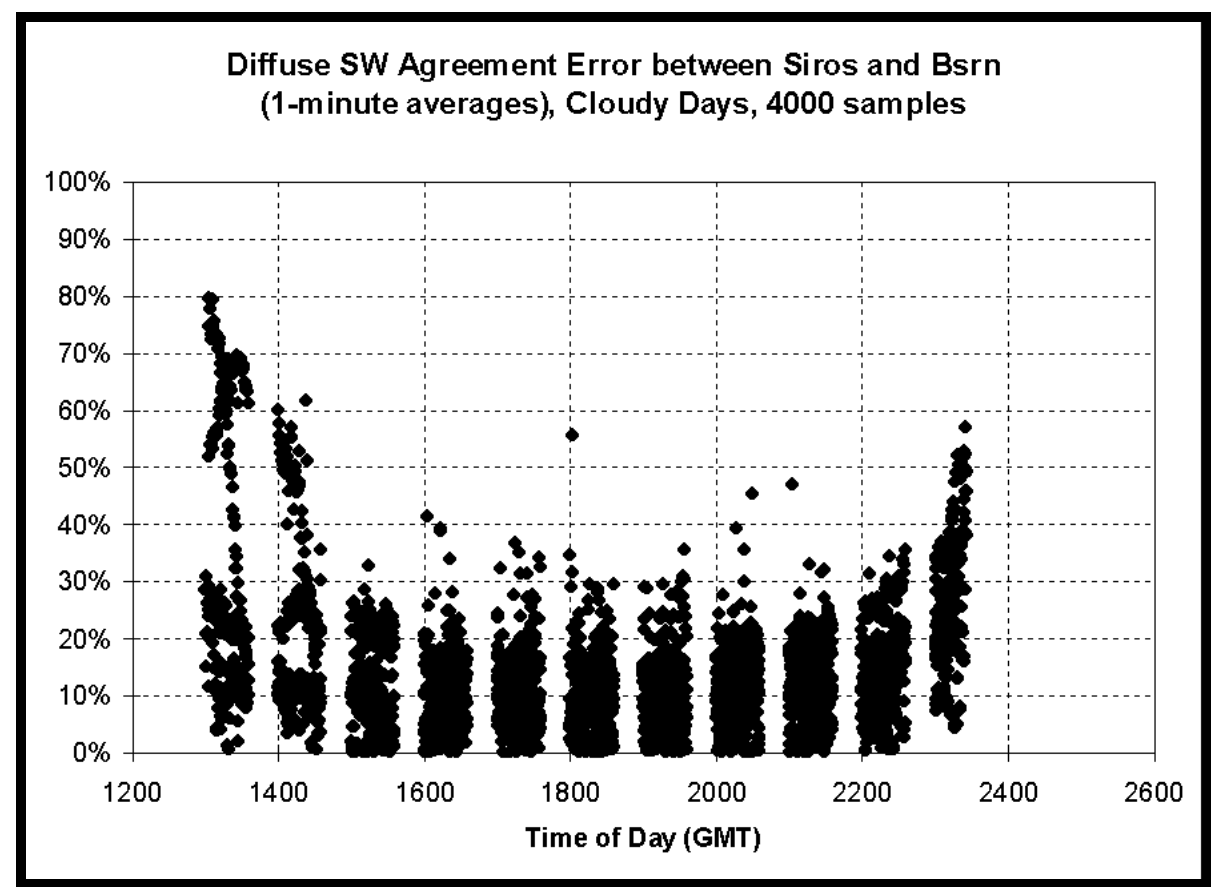

Figure 18. Similar to Figure 14, but using 1-minute data.

To help quantify the SIROS data logging issue, Figure 19 shows the change in the standard deviation from perfect agreement for the radiative components with changes in averaging time for both clear and cloudy days. For this plot, the BSRN direct normal malfunction period has been removed, but the BSRN diffuse shading disc-tracking problem has not. Thus, the diffuse standard deviations (Dif StD) for clear days are more than double what they are for periods when the arm was working properly. Nevertheless, this plot shows that for cloudy conditions the standard deviation in the diffuse measurements increases by about $20 \mathrm{Wm}-2$ over that for clear skies and longer averaging time has little effect on this disagreement. In fact, a longer averaging time has only a slight effect on any component for clear-sky conditions, which is expected. Part of the reason for the magnitude of these clear-sky disagreements stems from the noisiness of the SIROS system. Based on our examination of many plots of the data, the BSRN system seems to have a higher signal-to-noise ratio. This is not surprising since, in effect, each BSRN 1-minute measurement consists of an average of many instantaneous measurements, as opposed to the 3-per-minute instantaneous measurements from the SIROS system. Thus, these clear-sky standard deviations include both calibration offsets and this "noise" problem.

Longer averaging time has a dramatic effect on the total SW standard deviations (TSW StD) for cloudy days, increasing the agreement to a value of about $18 \mathrm{Wm}-2$ for 30-minute averages compared to $57 \mathrm{Wm}$-2 for 1-minute averages. Note that the TSW 30-minute agreement is actually better than that for 


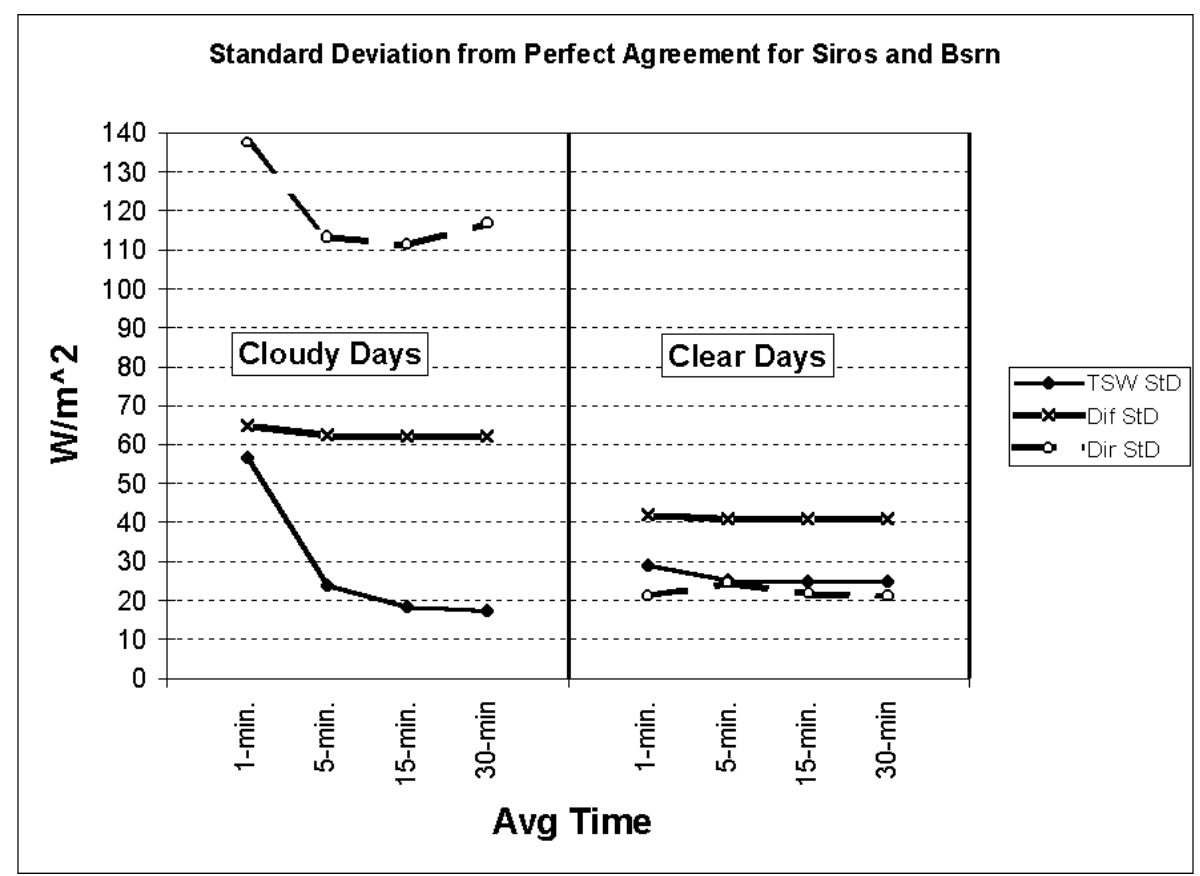

Figure 19. Standard Deviation from perfect agreement $(X=Y)$ for increasing averaging times for mostly clear and cloudy days for Total SW, Diffuse SW, and Direct Normal SW.

clear skies. This is a result of the decrease in magnitude of the irradiance field under cloudy conditions compared to clear skies. The direct normal standard deviations (Dir StD) show some improvement with longer averaging time, but still remain greater than $110 \mathrm{Wm}-2$ for all cases.

\section{Conclusion}

In summary, a few points should be noted. First, those who wish to use the total SW data from ARESE need to be notified of the BSRN radiometer change on the $13^{\text {th }}$, since it appears that the BSRN data, after the change at least, are the data of choice for temporal resolutions of 1 to 15 minutes. For the ARM Program, it seems obvious that the SIROS system should be converted to full 1-minute averages, as this is much more of a problem than instrument calibration appears to be, especially for cloudy skies. Also, we've found that logging the standard deviations of the 1-minute averages as well as the mean itself helps considerably in both estimating the variability of the average and, especially in the case of the diffuse measurements, quality control of the data. Finally, it seems logical that some type of on-site display of the data would be highly useful in helping the site personnel address some problems like the $2 \frac{1}{2}$ weeks of missing BSRN data, and the BSRN total SW drifting prior to the $14^{\text {th }}$ (shown in Figures 3,4 , 5, and 6). A simple graphical display at the central facility would allow on-site monitoring of these systems, and more efficient problem identification and repair. 